ORIGINAL ARTICLE

\title{
Is metal fume fever a determinant of welding related respiratory symptoms and/or increased bronchial responsiveness? A longitudinal study
}

\author{
M El-Zein, C Infante-Rivard, J-L Malo, D Gautrin
}

Occup Environ Med 2005;62:688-694. doi: 10.1136/oem.2004.018796

See end of article for authors' affiliations

Correspondence to: Dr D Gautrin, Department of Chest Medicine, SacréCoeur Hospital, 5400 Gouin Blvd West, Montreal, Canada, H4J 1C5; D-Gautrin@crhsc. umontreal.ca

Accepted 31 March 2005
Background: The current prospective study investigated the hypothesis of metal fume fever (MFF) being a predictor for the development of respiratory symptoms and functional abnormalities.

Methods: The study consisted of a pre-exposure and two follow up assessments of 286 welding apprentices during an average period of 15 months. A respiratory and a systemic symptom questionnaire, skin prick tests to common allergens and metal salts, spirometry, and methacholine challenge tests were administered.

Results: Developing at least one positive skin prick test to a metallic salt solution was found in $11.8 \%$ of apprentices. Possible MFF (at least one of fever, feelings of flu, general malaise, chills, dry cough, metallic taste, or shortness of breath) was reported by $39.2 \%$ of apprentices. The presence of at least one welding related respiratory symptom (cough, wheezing, or chest tightness) suggestive of welding related asthma was reported by $13.8 \%$. MFF was significantly associated with these respiratory symptoms $(O R=4.92$, $95 \% \mathrm{Cl} 2.10$ to 11.52), after adjusting for age, atopy, smoking, physician diagnosed asthma, and symptoms of non-welding related asthma. Apprentices with possible MFF, and no welding related respiratory symptoms suggestive of welding related asthma at the first follow up, had an increased risk of developing the latter symptoms by the second follow up visit (OR $=7.4,95 \% \mathrm{Cl} 1.97$ to 27.45 ) compared with those not having MFF. MFF was not significantly associated with an increase in bronchial responsiveness.

Conclusion: MFF could be a predictor for the development of respiratory symptoms but not for functional abnormalities in welders.
M etal fume fever (MFF) has been defined as a "flu-like illness that develops after inhalation of metal fumes with symptoms beginning 3-10 hours after exposure. Initially, there may be a sweet metallic taste in the mouth accompanied by a worsening dry cough and shortness of breath. Fever and shaking chills often develop and the worker feels ill. Workers develop tachyphylaxis-that is, symptoms appear only when the exposure occurs after several days without exposure, not when there are regular repeated exposures." ${ }^{11}$ Whether several recurrent episodes of MFF, experienced by welders, do resolve without causing respiratory impairment is unknown. Moreover, as MFF can be experienced on the first day by a new employee in the welding profession (that is, no latency period), whereas airway obstruction and respiratory symptomatology require some latency period, it is conceivable that MFF, occurring shortly after exposure, could be a risk factor for the further development of respiratory symptoms and/or increased bronchial responsiveness.

The contributing effect of welding fumes and gases to the development of asthma and occupational asthma has recently received attention. ${ }^{2}$ Gas metal arc welding on mild steel, a widely used welding technique, has been reported to cause asthmatic reactions after an occupational type challenge. ${ }^{3}$ There have also been several case reports of nickel induced occupational asthma, ${ }^{45}$ and of occupational asthma among stainless steel welders, ${ }^{67}$ entailing exposure to chromium IV, known to cause occupational asthma, ${ }^{8}$ as well as cases of occupational asthma related to exposure to zinc oxide fumes. ${ }^{9} 10$

In our previous descriptive cross sectional study of welding related systemic and respiratory symptoms in 441 welders, a strong association was found between MFF and welding related respiratory symptoms suggestive of welding related asthma. ${ }^{11}$ The objective of the current longitudinal study was to investigate the association between MFF and the incidence of welding related respiratory symptoms suggestive of welding related asthma, and/or increased bronchial responsiveness.

\section{MATERIALS AND METHODS}

\section{Study design}

The study consisted of a baseline pre-exposure assessment survey and two follow up assessments in apprentices starting vocational training in the welding profession. It took place between September 1998 and June 2001. The first follow up assessment was, on average, eight months after the baseline assessment, while the second follow up was conducted at an average of seven months after the first.

\section{Study subjects}

Seven teaching institutions offering vocational education programmes in welding in Montreal, Canada and surroundings were contacted. Four of these institutions agreed to participate in the study. The programme in question hosts 20 to 22 students per class and lasts 15-18 months. The programme consists of theoretical instruction in addition to practical sessions in the welding shop, where apprentices use mainly four major welding processes and three welded metals. The welding processes are shielded metal arc welding, gas metal arc welding, gas tungsten arc welding, and flux core arc welding. The time spent on each of these processes totals 120 hours or an equivalent, for eight hours of welding per day, to 15 days. The overall time spent by students (time 
being similar among schools) using these processes corresponds on average, in reference to eight hours per day of welding in a workshop, to approximately two months of exposure to welding fumes and gases. The welded metals mostly include stainless steel, mild steel, and aluminum; welding on galvanised steel is not used. Only students who had not been exposed to welding fumes and gases in the two months before the start of their apprenticeship and who had not welded for more than a year in their lifetime were included. A signed consent form was obtained from each participant and from one of his/her parents if he/she was under 18 years of age. The ethics committee for research of Sacré-Coeur Hospital approved the study.

\section{Diagnostic procedures \\ Questionnaire}

Two questionnaires were administered. The respiratory questionnaire, administered at baseline, was derived from the standardised questionnaire of the International Union against Tuberculosis and Lung Disease. ${ }^{12}$ The systemic symptom questionnaire, adapted from a questionnaire developed by Menzies and collaborators ${ }^{13}$ used in the follow up periods, related to respiratory and systemic symptoms and their time course.

\section{Skin testing}

IgE mediated sensitisation to common environmental allergens and to metal(s) was determined for all study subjects by skin prick tests. ${ }^{14}$ Histamine phosphate $(1 / 200 \mathrm{~g} / \mathrm{ml})$ was used as a positive control, and diluent (glycerine, 50\%), as a negative control. Skin tests were done using 11 common inhalants (mixed tress, mixed grass, and ragweed pollen; Altenaria; Aspergillus; Hormodendrum, feathers, Dermatophagoides farinae; Dermatophagoides pteronissinus; and cat and dog dander). Skin prick tests were also done with specific metals to which apprentice welders were exposed to, including: zinc, chromium, nickel, copper, iron, manganese, aluminum, and cadmium. Solutions were prepared at the Sacré-Coeur Hospital laboratory with the corresponding metallic salts ( $1 \mathrm{mg} / \mathrm{ml} \mathrm{NaCl}, 0.9 \%)$. The largest wheal diameter was assessed 10-15 minutes after introducing the antigen. A positive reaction was defined as a wheal diameter $\geqslant 3 \mathrm{~mm}$ in the absence of reaction to the diluent and in the presence of a positive reaction to histamine phosphate.

\section{Bronchial responsiveness testing}

Bronchial responsiveness was determined through methacholine inhalation tests ${ }^{15}$ using a Wright nebuliser (output $=0.14 \mathrm{ml} / \mathrm{min}$ ) at tidal volume breathing. We have previously reported that a total of $23(11.9 \%)$ of these apprentice welders, out of 194 subjects, had a significant increase in bronchial responsiveness (3.2-fold decrease in $\mathrm{PC}_{20}$ with respect to baseline value). ${ }^{16}$

\section{Study variables}

\section{Baseline host factors}

Indices to characterise host factors before entry into the apprenticeship were derived from the responses to the questionnaire and from results of the skin prick tests.

1. The presence of symptoms suggestive of non-welding related asthma was defined as at least two positive answers to questions about wheezing or whistling, chest tightness, shortness of breath, cough under usual conditions, and any of these four symptoms under conditions such as exercise, strenuous work, very cold air, strong smells, smoke, and dust.

2. Atopy was defined as the presence of at least two positive reactions to a common inhalant from the battery of 11 aeroallergens used (refer to methods for allergens used). This definition of atopy was previously used in a prospective cohort study of apprentices in animal health, pastry making, and dental hygiene. ${ }^{17}$

Risk factors (intermediate outcomes) detected during the course of the study

1. Possible MFF was defined as having at least one of fever, feelings of flu, general malaise, chills, dry cough, metallic taste, or shortness of breath, occurring 3-10 hours after exposure to welding fumes as reported by the welders.

2. The presence of immunological sensitisation (skin prick test reactivity) to metals was defined as the presence of at least one immediate positive skin reaction (response $\geqslant 3 \mathrm{~mm}$ ) to the eight metal solutions. Subjects who had immunological sensitisation to metals at the first but not at the second follow up visit were not considered as having developed skin prick test reactivity to metals.

\section{Main outcome measures}

1. Respiratory symptoms suggestive of welding related asthma were defined as the presence of either welding related cough, wheezing, or chest tightness. These symptoms were considered persistent if they have developed at the first follow up and persisted until the second follow up, or if they have developed at the second follow up. Of note, there was no overlap between respiratory symptoms suggestive of welding related asthma and those attributed to MFF (dry cough was a throat symptom used in defining MFF).

2. A drop in $\mathbf{P C}_{20}$ defined an increased bronchial responsiveness when there was a 3.2 -fold or greater ${ }^{18}$ decrease from the baseline to the second methacholine challenge test.

\section{Statistical analysis}

Descriptive statistics including frequencies along with their 95\% confidence intervals (CI) were calculated. Odds ratios (ORs) and 95\% CI were estimated to assess the association between possible MFF and the main outcome variables. Other potential risk factors were also considered. Univariate logistic regression analyses were carried out to identify potentially associated variables to the incidence of the main outcomes. These included MFF, immunological sensitisation to metals as risk factors and age, atopy, smoking, physician diagnosed asthma, and symptoms of non-welding related asthma as potential confounders. In the multiple logistic regression model, possible MFF and immunological sensitisation to metals were considered as exposure variables for the two outcomes studied and all potential confounders were included. The level of statistical significance was set at a p value less than or equal to 0.05 (two sided). Descriptive statistics and regression analyses were performed using SPSS-PC for Windows (Statistical Package for Social Sciences) (version 10, SPSS, Inc, Chicago, IL, USA).

\section{RESULTS}

From the four teaching institutions that offered a career programme in welding, 381 apprentice welders were invited to participate in the study. Of these, 81 students refused to take part and another 14 were excluded due to significant previous exposure to welding fumes (see eligibility criteria above). A total of 286 students (75.1\% of those eligible) were included in the study. The majority ( $89.4 \%$ ) had never been involved with welding operations in their lifetime; the others $(10.6 \%)$ had welded for a period ranging from 15 days to 
Table 1 Baseline symptomatology $(n=285)^{*}$

\begin{tabular}{|c|c|c|c|c|c|c|}
\hline & \multicolumn{3}{|c|}{$\begin{array}{l}\text { Subjects who completed the study } \\
\text { ( } n=203 \text { ) }\end{array}$} & \multicolumn{3}{|c|}{ Subjects lost to follow up ( $n=83$ ) } \\
\hline & n & $\%$ & $95 \% \mathrm{Cl}$ & n & $\%$ & $95 \% \mathrm{Cl}$ \\
\hline Wheezingt & 45 & 22.2 & 18.5 to 26.9 & 19 & 23.2 & 20.8 to 29.5 \\
\hline Chest tightness $†$ & 16 & 7.9 & 5.5 to 11.1 & 9 & 11.0 & 8.1 to 14.5 \\
\hline Shortness of breath $\dagger$ & 18 & 8.9 & 6.4 to 12.3 & 8 & 9.8 & 7.0 to 13.1 \\
\hline Cought & 15 & 7.4 & 5.1 to 10.5 & 7 & 8.5 & 6.1 to 11.7 \\
\hline Phlegm† & 32 & 15.8 & 11.7 to 18.9 & 23 & 28.0 & 23.2 to 32.2 \\
\hline $\begin{array}{l}\text { Symptoms of non-welding related } \\
\text { asthmał }\end{array}$ & 33 & 16.3 & 13.9 to 21.6 & 21 & 25.6 & 20.8 to 29.6 \\
\hline Asthma§ & 35 & 17.4 & 13.9 to 21.6 & 11 & 13.4 & 11.7 to 18.9 \\
\hline Familial asthma & 36 & 17.7 & 16.2 to 24.3 & 20 & 24.4 & 20.8 to 29.6 \\
\hline Personal atopic history ${ }^{\star *}$ & 80 & 39.8 & 35.2 to 45.0 & 22 & 26.8 & 23.2 to 32.2 \\
\hline Atopy†† & 96 & 47.3 & 42.5 to 52.5 & 36 & 44.4 & 40.1 to 50.0 \\
\hline Rhinitis with pets $\ddagger \ddagger$ & 76 & 37.4 & 32.8 to 42.5 & 18 & 22.0 & 18.5 to 26.9 \\
\hline Rhinitis in pollen season $\ddagger \ddagger$ & 66 & 32.5 & 27.9 to 37.3 & 18 & 22.0 & 18.5 to 26.9 \\
\hline Respiratory symptoms with pets§§ & 29 & 14.3 & 11.7 to 18.9 & 5 & 6.1 & 4.1 to 9.1 \\
\hline $\begin{array}{l}\text { Respiratory symptoms in pollen } \\
\text { season§§ }\end{array}$ & 15 & 7.4 & 5.1 to 10.5 & 4 & 4.9 & 3.1 to 7.6 \\
\hline \multicolumn{7}{|c|}{$\begin{array}{l}\text { *One subject who dropped out of the study did not complete questionnaire at baseline. } \\
\text { †Present in the last } 12 \text { months at the time of the interview. } \\
\text { PPresence of at least two positive answers to questions about wheezing, chest tightness, shortness of breath, or } \\
\text { cough under usual conditions or under such conditions as exercise, exposure to cold air, strong odours, smoke, } \\
\text { and dusts. } \\
\text { \$Physician confirmed as reported by subject. } \\
\text { TPresent if one of mother, father, or sister/brother has asthma. } \\
\text { **Present in the case of a history of eczema, urticaria, or hayfever. } \\
\text { †Presence of at least two immediate reactions to a battery of } 11 \text { common inhalants. } \\
\text { ††Presence of at least one of runny or stuffy nose, attack of sneezing, or itchy eyes. } \\
\S \S \text { Presence of at least one of cough for several minutes, wheezing, chest tightness, shortness of breath, or waking } \\
\text { up at night due to these symptoms. }\end{array}$} \\
\hline
\end{tabular}

12 months, but none had welded during the two months before their apprenticeship began. By the first follow up assessment, 54 apprentices had dropped out and nine were absent; thus we obtained data for 223 apprentices (78\% of those included at baseline). By the second follow up assessment, another 12 students had dropped out, seven were absent, and one refused to continue in the study, leaving 203/223 apprentices (91\% of those present at the first follow up). Therefore, by the end of the apprenticeship, 83/ 286 subjects had been lost to follow up (29\%). For those who remained until the end of the study, most were males
(82.8\%); mean age was 24.91 (SD 7.91 ) years with $48.8 \%$ aged less than 21 years. Only about a third (35.5\%) had never smoked, with slightly over $13 \%$ being heavy smokers $(\geqslant 20$ pack years).

Table 1 displays mainly respiratory symptomatology of study participants. At the end-of-study interview, $22.2 \%$ and $15.8 \%$ of the remaining 203 apprentices, respectively, reported having had wheezing and phlegm production during the last 12 months. Slightly more than $16 \%$ reported having had symptoms of non-welding related asthma. Close to half were atopic, with a high proportion sensitised to pollens,

Table 2 Incidence of symptoms* describing MFF $(n=232) \dagger$

\begin{tabular}{|c|c|c|c|c|c|c|c|c|c|c|}
\hline \multirow{3}{*}{$\begin{array}{l}\text { Welding related } \\
\text { symptoms }\end{array}$} & & & \multicolumn{4}{|c|}{ Persistent symptoms } & & & & \\
\hline & \multicolumn{2}{|c|}{$\begin{array}{l}\text { No symptom } \\
\text { reported at } \\
\text { any of the } \\
\text { follow up visits }\end{array}$} & \multicolumn{2}{|c|}{$\begin{array}{l}\text { Symptoms } \\
\text { reported in 1st } \\
\text { follow up visit } \\
\text { and persisted }\end{array}$} & \multicolumn{2}{|c|}{$\begin{array}{l}\text { Symptoms } \\
\text { reported as of } \\
2 \text { nd follow up } \\
\text { visit }\end{array}$} & \multicolumn{2}{|c|}{$\begin{array}{l}\text { Symptoms } \\
\text { present in 1st } \\
\text { but not in } 2 \text { nd } \\
\text { follow up visit }\end{array}$} & \multicolumn{2}{|c|}{$\begin{array}{l}\text { Symptoms reported } \\
\text { at one or the other } \\
\text { of the follow up } \\
\text { visits }\end{array}$} \\
\hline & $\mathbf{n}$ & $\%$ & $\mathbf{n}$ & $\%$ & $\mathbf{n}$ & $\%$ & $\mathbf{n}$ & $\%$ & $\mathbf{n}$ & $\%$ \\
\hline \multicolumn{11}{|l|}{ Flu-like } \\
\hline Fever & 213 & 91.8 & 3 & 1.3 & 6 & 2.6 & 10 & 4.3 & 19 & 8.2 \\
\hline Feelings of "flu" & 198 & 85.3 & 7 & 3 & 10 & 4.3 & 17 & 7.3 & 34 & 14.7 \\
\hline General malaise & 223 & 96.1 & 2 & 0.9 & 3 & 1.3 & 4 & 1.7 & 9 & 3.9 \\
\hline Chills & 211 & 90.9 & 5 & 2.2 & 8 & 3.4 & 8 & 3.4 & 21 & 9.1 \\
\hline \multicolumn{11}{|l|}{ Throat } \\
\hline \multicolumn{11}{|c|}{ Taste } \\
\hline Metallic taste & 171 & 73.7 & 21 & 9.1 & 30 & 12.9 & 10 & 4.3 & 61 & 26.4 \\
\hline Shortness of breath & 203 & 87.5 & 6 & 2.6 & 9 & 3.9 & 14 & 6 & 29 & 12.5 \\
\hline \multicolumn{11}{|c|}{$\begin{array}{l}\text { symptom suggestive } \\
\text { of MFF } \ddagger\end{array}$} \\
\hline $\begin{array}{l}\text { *Symptoms were co } \\
\text { the welders. } \\
\text { †45 apprentices ha } \\
\text { tHaving at least on } \\
\text { taste, shortness of b }\end{array}$ & $\begin{array}{l}\text { onside } \\
\text { ad dro } \\
\text { e of o } \\
\text { oreath }\end{array}$ & $\begin{array}{l}\text { present } \\
\text { d by th } \\
\text { ve listed }\end{array}$ & $\begin{array}{l}\text { fir } \\
\text { sym }\end{array}$ & $\begin{array}{l}\text { ccurred } \\
\text { ow up a } \\
\text { is (fever }\end{array}$ & S & of flu, ge & . & aise, $\mathrm{ch}$ & $d$ & eported by \\
\hline
\end{tabular}


Table 3 Skin test results to metal salt solutions*

\begin{tabular}{|c|c|c|c|c|c|c|c|c|c|c|}
\hline & \multirow{2}{*}{\multicolumn{2}{|c|}{$\begin{array}{l}\text { Never } \\
\text { developed } \\
\text { sensitisation }\end{array}$}} & \multicolumn{4}{|c|}{ Persistent sensitisation } & & & & \\
\hline & & & \multicolumn{2}{|c|}{$\begin{array}{l}\text { Developed } \\
\text { sensitisation as } \\
\text { of } 1 \text { st follow up } \\
\text { and persisted }\end{array}$} & \multicolumn{2}{|c|}{$\begin{array}{l}\text { Developed } \\
\text { sensitisation as } \\
\text { of } 2 \text { nd follow } \\
\text { up visit }\end{array}$} & \multicolumn{2}{|c|}{$\begin{array}{l}\text { Sensitisation } \\
\text { present in 1st } \\
\text { but not in } 2 \text { nd } \\
\text { follow up visit }\end{array}$} & \multicolumn{2}{|c|}{ Incidence } \\
\hline & $\mathrm{n}$ & $\%$ & $\mathbf{n}$ & $\%$ & $\mathbf{n}$ & $\%$ & $n$ & $\%$ & $\mathbf{n}$ & $\%$ \\
\hline Iron & 227 & 99.6 & & & 1 & 0.4 & & & 1 & 0.4 \\
\hline Aluminum & 227 & 99.6 & & & 1 & 0.4 & & & 1 & 0.4 \\
\hline Copper & 215 & 94.3 & & & 13 & 5.7 & & & 13 & 5.7 \\
\hline Manganese & 225 & 98.7 & 1 & 0.4 & 2 & 0.9 & & & 3 & 1.3 \\
\hline Zinc & 219 & 96.1 & & & 7 & 3.1 & 2 & 0.9 & 7 & 3.1 \\
\hline Nickel & 226 & 99.1 & & & 1 & 0.4 & 1 & 0.4 & 1 & 0.4 \\
\hline Chromium & 224 & 98.2 & 1 & 0.4 & 3 & 1.3 & & & 4 & 1.8 \\
\hline Cobalt & 228 & 100 & & & & & & & 0 & 0 \\
\hline At least one positive & 198 & 86.8 & 2 & 0.9 & 25 & 11.0 & 3 & 1.3 & $27 \dagger$ & 11.8 \\
\hline
\end{tabular}

*A positive response was defined as a wheal diameter $\geqslant 3 \mathrm{~mm}$.

†Those who developed sensitisation in first follow up and did not persist in the second follow up $(n=3)$ are not included.

mites, and animal dander $(44.3 \%, 36.0 \%$, and $27.1 \%$, respectively) (data not shown). The presence of rhinitis was reported by $37.4 \%$ on contact with pets and by $32.5 \%$ in the pollen season.

Table 2 presents the incidence of symptoms used in defining MFF. Apprentices mainly reported the development of a metallic taste $(26.4 \%)$, followed by feelings of flu, dry cough, and shortness of breath $(14.7 \%, 14.2 \%$, and $12.5 \%$, respectively). MFF, defined as having at least one of the symptoms mentioned in the table, was in the order of $39.2 \%$ throughout the study.

As shown in table 3, $11.8 \%$ developed immunological sensitisation to at least one metal solution throughout the study. Only two subjects developed sensitisation at the first follow up assessment, while the rest developed it later towards the end of their welding training. Apprentices mainly developed sensitisation to copper (5.7\%). Of note, one student was sensitised at baseline to aluminum, copper, manganese, and zinc and was, thus, later removed from the analysis for the development of immunological sensitisation to metals.

The incidence of welding related respiratory and systemic symptoms, as well as welding related nasal and ocular symptoms, according to their time of development (first or second follow up assessment) and persistence is provided in table 4. Nearly two thirds $(66.8 \%)$ of the subjects reported having experienced at least one of the mentioned systemic symptoms at least once during the study survey. Moreover, slightly more than a third $(33.2 \%)$ reported its presence persistently at the first and second follow up assessments. In comparison, $15.9 \%$ reported having at least one of the above mentioned systemic symptoms only at the first follow up visit. As for the incidence of welding related respiratory symptoms suggestive of welding related asthma, this was $13.8 \%$ at one or the other follow up visits. Participants experienced more cough $(9.9 \%)$ than wheezing $(5.2 \%)$ or

Table 4 Incidence of welding related symptoms $(n=232)^{*}$

\begin{tabular}{|c|c|c|c|c|c|c|c|c|c|c|}
\hline \multirow[b]{3}{*}{ Welding related symptoms } & \multirow{2}{*}{\multicolumn{2}{|c|}{$\begin{array}{l}\text { No symptom } \\
\text { reported at } \\
\text { any of the } \\
\text { follow up visits }\end{array}$}} & \multicolumn{4}{|c|}{ Persistent symptoms } & \multirow{2}{*}{\multicolumn{2}{|c|}{$\begin{array}{l}\text { Symptoms } \\
\text { present in 1st } \\
\text { but not in } \\
\text { 2nd follow } \\
\text { up visit }\end{array}$}} & \multirow{2}{*}{\multicolumn{2}{|c|}{$\begin{array}{l}\text { Symptoms } \\
\text { reported at } \\
\text { one or the } \\
\text { other of the } \\
\text { follow up visits }\end{array}$}} \\
\hline & & & \multicolumn{2}{|c|}{$\begin{array}{l}\text { Symptoms } \\
\text { reported in 1st } \\
\text { follow up visit } \\
\text { and persisted }\end{array}$} & \multicolumn{2}{|c|}{$\begin{array}{l}\text { Symptoms } \\
\text { reported as } \\
\text { of } 2 \text { nd follow } \\
\text { up visit }\end{array}$} & & & & \\
\hline & $\mathbf{n}$ & $\%$ & $\mathbf{n}$ & $\%$ & $\mathbf{n}$ & $\%$ & $\mathbf{n}$ & $\%$ & $\mathbf{n}$ & $\%$ \\
\hline \multicolumn{11}{|l|}{ Systemic } \\
\hline Flu-like & 179 & 77.2 & 12 & 5.2 & 14 & 6.0 & 27 & 11.6 & 53 & 22.8 \\
\hline Aches and pains & 193 & 83.2 & 14 & 6.0 & 5 & 2.2 & 20 & 8.6 & 39 & 16.8 \\
\hline Throat & 137 & 59.1 & 37 & 15.9 & 24 & 10.3 & 34 & 14.7 & 95 & 40.9 \\
\hline Digestive & 207 & 89.2 & 9 & 3.9 & 6 & 2.6 & 10 & 4.3 & 25 & 10.8 \\
\hline Taste & 165 & 71.1 & 29 & 12.5 & 24 & 10.3 & 14 & 6.0 & 67 & 28.9 \\
\hline Fatigue & 172 & 74.1 & 19 & 8.2 & 17 & 7.3 & 24 & 10.3 & 60 & 25.9 \\
\hline At least one & 77 & 33.2 & 77 & 33.2 & 41 & 17.7 & 37 & 15.9 & 155 & 66.8 \\
\hline At least one nasal symptom & 158 & 68.1 & 26 & 11.2 & 16 & 6.9 & 32 & 13.8 & 74 & 31.9 \\
\hline $\begin{array}{l}\text { At least one ocular } \\
\text { symptom }\end{array}$ & 174 & 75.0 & 14 & 6.0 & 17 & 7.3 & 27 & 11.6 & 58 & 25.0 \\
\hline \multicolumn{11}{|l|}{ Respiratory } \\
\hline Cough & 209 & 90.1 & 4 & 1.7 & 11 & 4.7 & 8 & 3.4 & 23 & 9.9 \\
\hline Wheezing & 220 & 94.8 & 3 & 1.3 & 4 & 1.7 & 5 & 2.2 & 12 & 5.2 \\
\hline Chest tightness & 219 & 94.4 & 3 & 1.3 & 6 & 2.6 & 4 & 1.7 & 13 & 5.6 \\
\hline $\begin{array}{l}\text { At least one symptom } \\
\text { suggestive of welding } \\
\text { related asthma† }\end{array}$ & 200 & 86.2 & 7 & 3.0 & 12 & 5.2 & 13 & 5.6 & 32 & 13.8 \\
\hline
\end{tabular}


Table 5 Association between potential risk factors and outcomes at follow up periods

\begin{tabular}{|c|c|c|c|c|c|c|}
\hline \multirow[b]{4}{*}{ Potential risk factors } & \multicolumn{6}{|l|}{ Main outcomes } \\
\hline & \multirow{2}{*}{\multicolumn{2}{|c|}{$\begin{array}{l}\text { First follow up } \\
\begin{array}{l}\text { At least } 1 \text { respiratory symptom } \\
(n=20)\end{array}\end{array}$}} & \multicolumn{4}{|c|}{ Second follow up } \\
\hline & & & \multicolumn{2}{|c|}{$\begin{array}{l}\text { At least } 1 \text { respiratory symptom } \\
(n=15)\end{array}$} & \multicolumn{2}{|c|}{ Increase in $\mathrm{BR}^{*}(\mathrm{n}=23)$} \\
\hline & $\mathrm{n}(\%)$ & OR $(95 \% \mathrm{Cl})$ & $\overline{n(\%)}$ & OR $(95 \% \mathrm{Cl})$ & $\overline{n(\%)}$ & OR $(95 \% \mathrm{Cl})$ \\
\hline \multicolumn{7}{|l|}{ Baseline } \\
\hline $\begin{array}{l}\text { Yes } \\
\text { No }\end{array}$ & $\begin{array}{l}12 / 109(11.0) \\
8 / 113(7.1)\end{array}$ & $1.62(0.64-4.14)$ & $\begin{array}{l}7 / 96(7.3) \\
8 / 107(7.5)\end{array}$ & $0.97(0.34-2.79)$ & $\begin{array}{l}10 / 89(11.2) \\
13 / 105(12.4)\end{array}$ & $0.90(0.37-2.15)$ \\
\hline \multicolumn{7}{|l|}{ Atopy } \\
\hline $\begin{array}{l}\text { Yes } \\
\text { No }\end{array}$ & $\begin{array}{l}12 / 107(11.2) \\
8 / 115(7.0)\end{array}$ & $1.69(0.66-4.31)$ & $\begin{array}{l}5 / 96(5.2) \\
10 / 107(9.3)\end{array}$ & $0.53(0.18-1.62)$ & $\begin{array}{l}15 / 93(16.1) \\
8 / 101(7.9)\end{array}$ & $2.24(0.90-5.55)$ \\
\hline \multicolumn{7}{|l|}{$\begin{array}{l}\text { No } \\
\text { Asthmał }\end{array}$} \\
\hline $\begin{array}{l}\text { Yes } \\
\text { No }\end{array}$ & $\begin{array}{l}2 / 39(5.1) \\
18 / 182(9.9)\end{array}$ & $0.49(0.11-2.22)$ & $\begin{array}{l}3 / 34(8.8) \\
12 / 167(7.2)\end{array}$ & $1.25(0.33-4.69)$ & $\begin{array}{l}5 / 34(14.7) \\
18 / 158(11.4)\end{array}$ & $1.34(0.46-3.90)$ \\
\hline \multicolumn{7}{|l|}{ Symptoms of asthma§ } \\
\hline $\begin{array}{l}\text { Yes } \\
\text { No }\end{array}$ & $\begin{array}{l}5 / 41(12.2) \\
15 / 181(8.3)\end{array}$ & $1.54(0.52-4.50)$ & $\begin{array}{l}3 / 33(9.1) \\
12 / 170(7.1)\end{array}$ & $1.32(0.35-4.95)$ & $\begin{array}{l}6 / 34(17.6) \\
17 / 160(10.6)\end{array}$ & $1.80(0.65-4.97)$ \\
\hline \multicolumn{7}{|l|}{$\begin{array}{l}\text { 1st follow up } \\
\text { Possible MFF }\end{array}$} \\
\hline Yes & $8 / 54(14.8)$ & $2.44(0.92-6.41)$ & $6 / 46(13.0)$ & $2.55(0.84-7.78)$ & $5 / 43(11.6)$ & $1.11(0.38-3.24)$ \\
\hline \multirow{2}{*}{\multicolumn{7}{|c|}{ Sensitisation }} \\
\hline & & $2.54(0.27-23.89)$ & & & & \\
\hline No & $19 / 212(9.0)$ & & $14 / 184(7.6)$ & & $18 / 178(10.1)$ & \\
\hline \multicolumn{7}{|l|}{ 2nd follow up } \\
\hline Yes & & & $12 / 50(24.0)$ & $15.58(4.19-57.99)$ & $8 / 49(16.3)$ & $1.65(0.65-4.18)$ \\
\hline No & & & $3 / 151(2.0)$ & & $15 / 142(10.6)$ & \\
\hline \multicolumn{7}{|l|}{ Sensitisation } \\
\hline Yes & & & $1 / 27(3.7)$ & $0.43(0.05-3.40)$ & $4 / 26(15.4)$ & $1.40(0.44-4.49)$ \\
\hline No & & & $14 / 170(8.2)$ & & $19 / 165(11.5)$ & \\
\hline \multicolumn{7}{|c|}{$\begin{array}{l}\text { *3.2-fold decrease in PC20. } \\
\text { †Current versus non- and ex-smokers. } \\
\text { †Physician diagnosed asthma as reported by subject. } \\
\text { §Symptoms of non-welding related asthma. }\end{array}$} \\
\hline
\end{tabular}

chest tightness $(5.6 \%)$. Seven subjects persistently reported having at least one of cough, wheezing, or chest tightness; symptoms that are considered to be suggestive of welding related asthma.

Table 5 examines the association between potential risk factors for the incidence of welding related respiratory symptoms suggestive of welding related asthma and for increased bronchial responsiveness within separate follow up periods. Possible MFF at the first follow up visit was only marginally significantly associated with respiratory symptoms suggestive of welding related asthma during the same visit. A marginal significant association was also found between atopy and increased bronchial responsiveness. Possible MFF was mostly associated with respiratory symptoms suggestive of welding related asthma $(\mathrm{OR}=15.58$, CI 4.19 to 57.99$)$ at the same second follow up visit. After adjusting for age, atopy, smoking, physiciandiagnosed asthma and symptoms of non-welding related asthma, possible MFF remained significantly associated with welding related respiratory symptoms suggestive of welding related asthma (table 6), whether present at one of the follow up surveys $(\mathrm{OR}=4.92,95 \%$ CI 2.10 to 11.52$)$ or persistent throughout the two follow up periods ( $\mathrm{OR}=13.72,95 \% \mathrm{CI}$ 3.63 to 51.84). Furthermore, table 7 shows that apprentices with possible MFF and no respiratory symptoms suggestive of welding related asthma at the first follow up were at an increased risk of developing respiratory symptoms suggestive of welding related asthma by the second follow up visit.

\section{DISCUSSION}

This prospective study, carried out in apprentices starting a career in welding, showed that MFF is associated with respiratory symptoms suggestive of welding related asthma, whether they occurred at one of the follow up surveys or persisted throughout both follow up surveys. This was found even when taking into account relevant potential risk factors for this outcome such as smoking. However, this study failed to reveal an effect of MFF on the incidence of increased bronchial responsiveness.

Although MFF symptoms have been described extensively in the literature, no generally standardised accepted definition is available. A prevalence of $31 \%$ for $\mathrm{MFF}^{19}$ and a prevalence of over $35 \%{ }^{20}$ was reported, but an exact definition was not provided. The incidence of possible MFF obtained in this study (based on the definition provided in the Encyclopedia of Occupational Health and Safety $)^{1}$ is nearly double the prevalence proportion (19.7\%) obtained from our previous cross sectional study. ${ }^{11}$ This could be explained by the fact that the latter study used a stricter definition of possible MFF-that is, having two instead of one of the symptoms previously described. We used a less stringent definition among apprentices because their exposure to welding fumes and gases is much less intense and of shorter duration/day than the exposure of welders employed in actual welding shops. It is noteworthy that the incidence of possible MFF using the same definition as in our previous prevalence study was $15.9 \%$ (37 apprentices), where out of these 23 were considered to have persistent symptoms of MFF ( 10 cases reported symptoms in the first follow up visit that persisted, 13 reported symptoms as of second follow up) and 14 reported symptoms as of the first but not in the second follow up visit. The presence of two symptoms suggestive of MFF was also not significantly associated with increased bronchial responsiveness ( $\mathrm{OR}=2.21$, 95\% CI 0.72 to 6.74), after adjusting for age, atopy, smoking, physician diagnosed asthma, and symptoms of non-welding related 
Table 6 Association between possible MFF and welding related respiratory symptom suggestive of welding related asthma and increase in bronchial responsiveness in multiple logistic regression analysis*

\begin{tabular}{|c|c|c|c|}
\hline & $\begin{array}{l}\text { At least one welding } \\
\text { related respiratory } \\
\text { symptoms }(n=32)\end{array}$ & $\begin{array}{l}\text { Persistent welding related } \\
\text { respiratory symptoms } \\
(\mathrm{n}=19)\end{array}$ & Increase in $B R(n=23)$ \\
\hline & OR $(95 \% \mathrm{Cl})$ & OR $(95 \% \mathrm{Cl})$ & OR $(95 \% \mathrm{Cl})$ \\
\hline Possible MFF ( $n=91$ ) & $4.92(2.10-11.52)$ & $13.72(3.63-51.84)$ & $1.26(0.49-3.24)$ \\
\hline
\end{tabular}

asthma. Furthermore, in our working welders study, another criterion that had to be met for a welder to be classified as having possible MFF was that the relevant symptoms of possible MFF had to occur at the beginning of the working week. This was impossible to apply in the current study as the apprentices could begin welding on any day, and not necessarily at the start of a given week. Following the same reasoning, our definition of welding related respiratory symptoms suggestive of welding related asthma was less conservative; it was set at having one $(13.8 \%)$ rather than two (14.6\% among working welders) of welding related symptoms of cough, wheezing, or chest tightness. Of note, the incidence of having at least two respiratory symptoms suggestive of welding related asthma was $5.6 \%$ (13 cases), where out of these 10 were considered to have persistent respiratory symptoms (two cases reported symptoms in the first follow up visit that persisted, eight reported symptoms as of second follow up) and three reported symptoms as of the first but not in the second follow up visit. We found no significant association between the incidence of welding related respiratory symptoms and baseline respiratory symptoms or rhinitis in the pollen season or on contact with pets. Worth noting is that most of these apprentices did not use respiratory protective equipment, and the few who did used inappropriate paper mask respirators. Moreover, in addition to the overall ventilation system, each apprentice welder had his/her separate welding booth with a ventilation mechanism at the source. An exposure assessment was carried out quantifying the concentration of metal fumes present in the breathing zone of apprentice welders while using the four welding processes previously mentioned. Results are presented elsewhere (submitted for publication).

As the pathophysiological mechanisms for asthma caused by low molecular weight agents are still poorly understood and as there is some evidence that occupational asthma due to exposure to metals may be induced through an $\operatorname{IgE}$ mediated mechanism, which is the case for platinum salts nickel and zinc, ${ }^{21}$ immunological sensitisation to metals was

Table 7 Association between possible MFF at first follow up visit in subjects with no welding related respiratory symptoms suggestive of welding related asthma and the presence of the latter at second follow up visit

\begin{tabular}{lllr}
\hline & \multicolumn{2}{l}{$\begin{array}{l}\text { Respiratory symptoms } \\
\text { at 2nd follow up }\end{array}$} & \\
\cline { 2 - 3 } & Yes, $\mathbf{n}(\%)$ & No, $\mathbf{n}(\%)$ & Total \\
\hline MFF at 1st follow up & $4(22.2)$ & $14(77.8)$ & 18 \\
Yes & $8(3.7)$ & $206(96.3)$ & 214 \\
No & 12 & 220 & 223 \\
Total & OR $=7.4(95 \%$ Cl 1.97 to 27.45) \\
\hline
\end{tabular}

considered in this study because of its significant incidence $(12 \%)$. Interestingly, in our study, copper salt sensitisation was the most common instance of sensitisation, followed by zinc and chromium. Although the latter two have been found to cause IgE dependent sensitisation, this has never been documented in the case of copper, to the best of our knowledge. However, skin sensitisation was not significantly associated with symptoms of welding related asthma. Such a negative finding, however, does not necessarily rule out an immunological mechanism, as specific IgE were not directly assessed nor did we carry out a lymphocyte transformation test, which has been advocated. ${ }^{22}$

The association between MFF and welding related respiratory symptoms suggestive of welding related asthma has never been looked at prospectively in the literature. Our recent cross sectional survey showed co-occurrence of possible MFF along with welding related respiratory symptoms suggestive of welding related asthma present in $5.8 \%$ of 351 working welders. ${ }^{11}$ We noted a significant association between MFF and welding related respiratory symptoms suggestive of welding related asthma. The current study has also suggested such an association, but this finding should still be cautiously considered due to the large confidence intervals found for the odds ratio.

Smoking has been associated with increased prevalence of respiratory symptoms and lung function impairment among smoking welders. ${ }^{23}{ }^{24}$ However, smoking in the current study did not seem to have any effect on welding related respiratory symptoms suggestive of welding related asthma or on the increase in bronchial responsiveness. ${ }^{16}$ Although a high proportion of apprentice welders were current smokers, the absence of such effects may probably be due to the relatively young age of the subjects considered and the short smoking history. Even so, our previous cross sectional study of welders, ${ }^{11}$ with considerably longer periods of exposure to welding fumes and gases, has shown that the frequency of respiratory and systemic symptoms was not different for welders who were current smokers than for ex-smokers or non-smoking welders.

As previously stated, 83 of 286 subjects (29\%) dropped out of the apprenticeship. Only one student refused to take part in the study at the second follow up assessment, while the majority who were lost to follow up had actually quit the apprenticeship shortly following the baseline assessment survey. Although apprentice welders who dropped out of the programme were not contacted, we believe that the short duration between enrolling and dropping out excludes possible self-selection out of the apprenticeship because of welding related health complaints after entry into the programme. Those who were lost to follow up in the current study did not differ in terms of baseline demographic characteristics from those who remained until the end of apprenticeship. However, close examination of pre-exposure symptomatology documented at entry into the study reveals that a significantly higher proportion of apprentices lost to 


\section{Main messages}

- The incidence of metal fume fever, welding related respiratory symptoms suggestive of welding related asthma, and immunological sensitisation to metals was increased in this group of welders after 15-18 months of apprenticeship.

- Metal fume fever might be a predictor of welding related respiratory symptoms suggestive of welding related asthma.

follow up had phlegm and symptoms of non-welding related asthma. On the other hand, a significantly lower proportion of apprentices lost to follow up had personal atopic history, rhinitis with pets and in the pollen season, as well as respiratory symptoms with pets. Therefore, there may have been some self-selection out of the programme due to nonoccupational respiratory symptomatology. However, as these characteristics were not associated with the outcomes studied here, a possible self-selection out of the programme is not likely to have affected our findings. A prior cohort study of 769 apprentices starting career programmes in animal health technology, pastry making, and dental hygiene technology have shown that welding related symptoms during training were not associated with quitting, although the presence of specific sensitisation before the start of apprenticeship was. ${ }^{25}$

The finding that MFF was not found to be a potential predictor for increased bronchial responsiveness could be explained by several possible reasons. One possible explanation is that the respiratory symptoms were indeed induced by exposure to welding fumes and gases, but were not a manifestation of welding related asthma. Another possibility is that these symptoms represent very mild or early signs of welding related asthma not detected by bronchial reactivity testing. This can also be related to the way airway responsiveness was measured. We determined bronchial responsiveness through methacholine inhalation tests while using other agents like adenosine monophosphate has been suggested. ${ }^{26}$ Furthermore, we did not investigate the presence of markers of inflammation that can be detected by examination of induced sputum and the assessment of exhaled nitric oxide. ${ }^{27}$

Overall, our study revealed that symptoms related to MFF were associated with developing welding related respiratory symptoms suggestive of welding related asthma.

\section{ACKNOWLEDGEMENTS}

The authors acknowledge the collaboration of the responsible authorities and the professors of the participating teaching institutions as well as all apprentice welders for taking part in the study. They specifically wish to thank the technicians, especially Carole Trudeau, RT and Simone Chaboillez, RT, and the nurse Michèle Magnan, RN responsible for data collection. The authors express their appreciation to Heberto Ghezzo, PhD for his statistical judgment.

\section{Authors' affiliations}

M El-Zein, C Infante-Rivard, Joint Departments of Epidemiology and Biostatistics and Occupational Health, McGill University, Montreal, Canada

J-L Malo, D Gautrin, The Department of Chest Medicine, Hôpital du Sacré-Coeur, Montreal

\section{Policy implications}

- The use of effective personal protective equipment should be emphasised at the apprenticeship level in teaching institutions offering a career programme in the welding profession.

Grant sponsor: Québec Pulmonary Association.

\section{REFERENCES}

1 Ryon DLS, Rom WN. Diseases caused by respirartory irritants and toxic chemicals. In: Stellman JM, ed. ILO Encyclopedia of occupational health and safety. Geneva: ILO, 1997:12-18.

2 Contreras GR, Chan-Yeung M. Bronchial reactions to exposure to welding fumes. Occup Environ Med 1997;54:836-9.

3 Vandenplas O, Dargent F, Auverdin JJ, et al. Occupational asthma due to gas metal arc welding on mild steel. Thorax 1995;50:587-8.

4 Block GT, Yeung M. Asthma induced by nickel. JAMA 1982;247:1600-2.

5 Malo JL, Cartier A, Doepner M, et al. Occupational asthma caused by nickel sulfate. J Allergy Clin Immunol 1982;69:55-9.

6 Keskinen H, Kalliomaki PL, Alanko K. Occupational asthma due to stainless steel welding fumes. Clin Allergy 1980;10:151-9.

7 Moller DR, Brooks SM, Bernstein DI, et al. Delayed anaphylactoid reaction in a worker exposed to chromium. J Allergy Clin Immunol 1986;77:451-6.

8 Toren K. Self reported rate of occupational asthma in Sweden 1990-2. Occup Environ Med 1996:53:757-61.

9 Kawane H, Soejima R, Umeki S, et al. Metal fume fever and asthma. Chest 1988;93:1116-17.

10 Malo JL, Cartier A. Occupational asthma due to fumes of galvanized metal. Chest 1987;92:375-7.

11 El-Zein M, Malo JL, Infante-Rivard C, et al. Prevalence and association of welding related systemic and respiratory symptoms in welders. Occup Environ Med 2003;60:655-61.

12 Burney $\mathbf{P}$, Laitinen L, Perdrizet S, et al. Validity and repeatability of the IUATLD (1984) bronchial symptoms questionnaire: an international comparison. Eur Respir J 1989;2:940-5.

13 Menzies R, Tamblyn R, Farant JP, et al. The effect of varying levels of outdoorair supply on the symptoms of sick building syndrome. N Engl J Med 1993;328:821-7.

14 Pepys J. Types of allergic reaction. Clin Allergy 1973;3(Suppl):491-509.

15 Cockcroft DW, Killian DN, Mellon JJ, et al. Bronchial reactivity to inhaled histamine: a method and clinical survey. Clin Allergy 1977;7:235-43.

16 El-Zein M, Malo JL, Infante-Rivard C, et al. Incidence of probable occupational asthma and changes in airway calibre and responsiveness in apprentice welders. Eur Respir J 2003;22:513-18.

17 Gautrin D, Ghezzo H, Infante-Rivard C, et al. Incidence and determinants of IgE-mediated sensitization in apprentices. A prospective study. Am J Respir Crit Care Med 2000;162:1222-8.

18 Dehaut P, Rachiele A, Martin RR, et al. Histamine dose-response curves in asthma: reproducibility and sensitivity of different indices to assess response. Thorax 1983:38:516-22.

19 Ross DS. Welders' metal fume fever. J Soc Occup Med 1974;24:125-9.

20 Kilburn K, Warshaw R, Boylen C, et al. Respiratory symptoms and functional impairment from acute (cross-shift) exposure to welding gases and fumes. Am J Med Sc 1989;298:314-19.

21 Bernstein L, Nemery B, Brooks S. Metals. In: Bernstein I, Chan-Yeung M, Malo J-L, Bernstein D, eds. Asthma in the workplace. New York: Marcel Dekker, Inc, 1999:501-21

22 Kusaka Y, Nakano Y, Shirakawa T, et al. Lymphocyte transformation test with nickel in hard metal asthma: another sensitizing component of hard metal. Ind Health 1992;29:153-60.

23 Groth M, Lyngenbo O. Respiratory symptoms in Danish welders. Scan J Soc Med 1989;17:271-6.

24 Rastogi S, Gupta B, Husain T, et al. Spirometric abnormalities among welders. Env Res 1991;56:15-24.

25 Monso E, Malo J, Infante-Rivard C, et al. Individual characteristics and quitting in apprentices exposed to high-molecular-weight agents. Am J Respir Crit Care Med 2000;161:1508-12.

26 Oosterhoff Y, Jansen MA, Postma DS, et al. Airway responsiveness to adenosine $5^{\prime}$-monophosphate in smokers and nonsmokers with atopic asthma. J Allergy Clin Immunol 1993;92:773-6.

27 Lemiere C. Non-invasive assessment of airway inflammation in occupational lung diseases. Curr Opin Allergy Clin Immunol 2002;2:109-14. 